\title{
FEM Based Improvement of CAD for Non-Conventional Railway Track
}

\author{
M. URBANEK* AND D. BlasZKIEWICZ \\ Cracow University of Technology, Kraków, Poland
}

\begin{abstract}
This paper shows a new method for numerical modelling of railway track in Autodesk Symulation Multiphisics software. The model of non-conventional railway foundation type of LONGASF is analysed. The improvement of modelling process of railway track considered as a structure consisting of separately modelled components is presented as the main novelty of the paper. The created model aims to improve design capabilities associated with change of individual material properties and, consequently, the change of railway track structure. This model allows an analysis of many railway tracks, depending on their material solutions. The obtain results are analysed in order to formulate the guidelines for design of this type of railway track.
\end{abstract}

DOI: 10.12693/APhysPolA.128.B-241

PACS: 02.70.Dh

\section{Introduction}

Implementation of new modelling methods for railway tracks in both cases the ballasted track and the slab track requires various experiments, including numerical analysis being a basis for further design [1]. Designing of the railway track needs a consideration of a large size structure and repeatability of its components (slippers, fastening system, rail).

This paper presents a new implementation of the finite element method to numerical analysis of nonconventional track, i.e. the ballastless one. Similar studies can be found in the literature in case of conventional tracks [2-7].

In order to develop a new method using a multilayer approach in the case of the railway structure design with non-conventional track a set of Finite Element Models should be developed. For this purpose, one can perform numerical analysis of the compressed concrete slippers in order to compare results with partially done experimental measurements [8].

To analyse an accordance of models with real structures [8], a set of experiments is performed using a laboratory sample. Bearing capacity of the construction is then assessed and compared with values obtained from numerical simulations. This method allows the transition from micro to macro scale and gives the opportunity to make changes in selection of materials criteria. It also enables the designers to carry out additional simulations that require considerable distance along the track, e.g. in the case of braking analysis.

A number of experiments are performed using a laboratory LONGASF construction sample. Non-conventional railway track called LONGASF, mentioned in this paper, is designed on foundation typical for roads (Fig. 1).

*corresponding author; e-mail: malgorzataurbanek@gmail.com

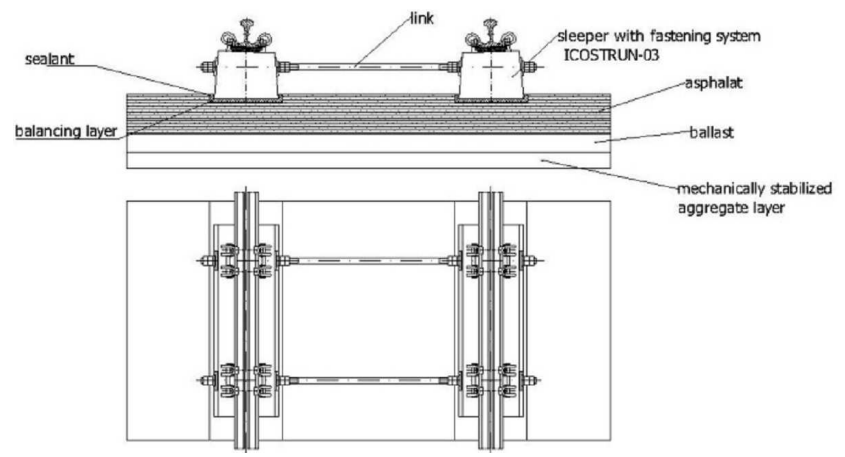

Fig. 1. LONGASF railroad track diagram [8].

\section{Laboratory tests}

Laboratory tests (Fig. 2) are carried out using sample with relatively small size, compared to the dimensions of the actual railway structure. The dimensions of the asphalt surface are limited to the length of 1.5 meters and the width of 3.0 meters [1]. During the performed tests the vertical and horizontal displacements of rail are measured. One can show that the maximum vertical displacement of the rail is around $2.5 \mathrm{~mm}$ and the maximum horizontal displacement of rail is estimated near $4.6 \mathrm{~mm}$. Such high value of displacement appears due to the lack of influence of neighboring fastenings.

Studies of the LONGASF rail track with the fastening system ICOSTRUN-03 are carried out according to the standards PN-EN 13481-5:2004 "Railway applications Track - Performance requirements for fastening systems - part 5" [2].

\section{Development and analysis of the model}

The three-dimensional model of the rail track LONGASF is created using Autodesk Simulation Multiphysics software on the basis of the laboratory model. It consists of a 3D placeholder (brick) and actuator which 


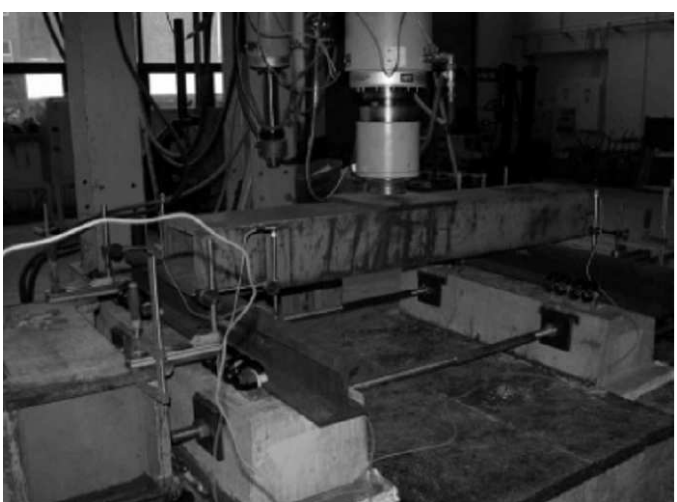

Fig. 2. LONGASF sample with ICOSTRUN 03 during stiffness tests [1].

can be used in order to fix the fastening system as shown in Figs. 3 and 4.

Subgrade the layer under asphalt is modelled by a spring element.

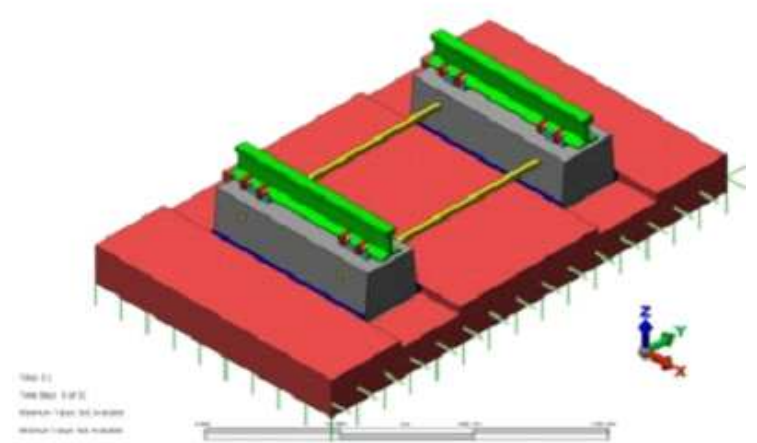

Fig. 3. Numerical model created in Autodesk Simulation Multiphysics.

In order to check the influence of adjacent fastenings on the structure sample 3D model, the length of the sample should be extended. With such a method the behaviour of the railway can be analysed and significant dimensions disparities along with the repetition of elements can be observed, for example one can describe the ratio of the object width to its length.

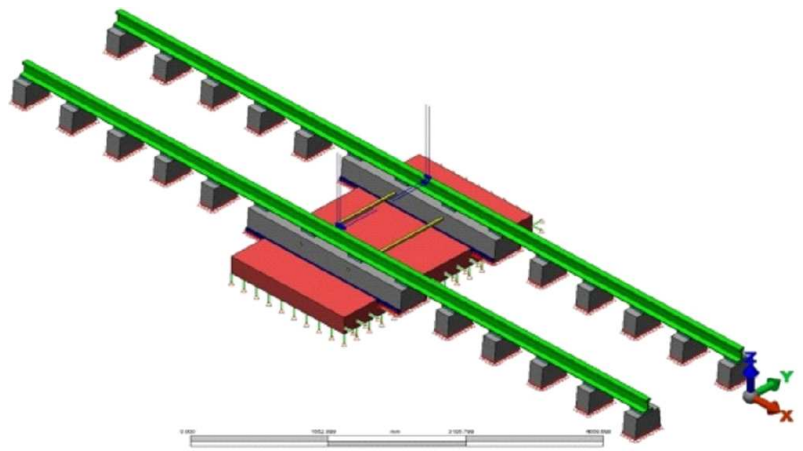

Fig. 4. Extended numerical model created in Autodesk Simulation Multiphysics.
The maximum vertical displacement is equal to $2.4 \mathrm{~mm}$, which is the result not significantly far from laboratory tests. The performed simulations show the maximum horizontal displacements are of around $2.4 \mathrm{~mm}$. This result is significantly different from the laboratory tests results, indicating the influence of the adjacent fastening.

The developed numerical model allows the consideraton of many material choices. In computer simulations various types of the subgrade, fastening components (rail pads) and asphalt substrate can be used. This leads to the optimal selection of railway track components.

\section{Summary}

In this paper a comparative study of the laboratory and numerical models of the rail displacement in railway track is carried out. The results of the numerical simulations are consistent with the laboratory measurements. The accuracy of the results indicate that the appropriate parameters are chosen for numerical modelling of the sample. Therefore the presented 3D modelling approach may be used to support design of rail track structures leading to possible design improvements.

One can say that the main objective of the analysis undertaken during experiments, i.e. formation of the modelling method allowing designers to be able to take into account a wide variability of mechanical and geometrical prosperities of railway track, is achieved. It is recommended to use the described methodology in order to decrease the computational costs of designing process.

\section{References}

[1] J. Kukulski, Problemy kolejnictwa 148, 207 (2009), (in Polish).

[2] K. Sakdirat, A.M. Remennikov, Eng. Fail. Anal. 16, 705 (2009).

[3] K. Sakdirat, A.M. Remennikov, NDTEE Int. 40, 510 (2007).

[4] K. Sakdirat, A.M. Remennikov, Eng. Fail. Anal., 2008.

[5] K. Sakdirat, A.M. Remennikov, The tenth East Asia - Pacific Conference on Structural Engineering and Construction, Bangkok 2005, p. 323.

[6] M.M. Shokrieh, R. Meysam, Compos. Struct. 76, 326 (2006).

[7] Modeling of the track subgrade, INNOTRACK Report Project No. TPI5-CT-2006-031415.

[8] W. Czyczuła, R. Bogacz, J. Stawowiak, S. Lisowski, M. Urbanek, D Kudła, D. Błaszkiewicz, A. PawlakBurakowska, Report from Railway track with a higher standard and reduced impact on the environment, project number: NR10-0004-10/2010, Kraków 2013.

[9] PN EN 13481-5:2004 Railway applications - Track - Performance requirements for fastening systems, part 5 . 